\title{
PLANEJAMENTO AMBIENTAL E A PERSPECTIVA ESCALAR: UMA ABORDAGEM GEOGRÁFICA
}

Ricardo dos Santos ${ }^{1}$ Edson Luís Piroli ${ }^{2}$

Resumo: Este trabalho tem como objetivo refletir sobre a escala geográfica, analisando-a com fundamento em suas contribuições para o entendimento do planejamento ambiental no contexto atual, e a partir de sua ótica, identificar possíveis articulações escalares no âmbito da Geografia. Como procedimentos metodológicos foram realizados levantamentos bibliográficos de obras e autores que discutem estes temas. Os resultados obtidos permitiram identificar que no âmbito da discussão do planejamento ambiental na perspectiva escalar, sociedade e natureza possuem apreensões escalares diferenciadas, resultantes de ritmos e dinâmicas distintas, relacionando-se com diferentes territórios no movimento interescalar e multiescalar. E o movimento dinâmico e recíproco entre seus elementos concretos e abstratos, se correlaciona e se inter-relaciona, constituindo-se diferentes perspectivas escalares. Em todo e qualquer planejamento sempre há uma proposta de intervenção/ação política que remete a uma concepção escalar do mundo social, nem sempre favorável a toda sociedade. Esta situação pode ser revertida, garantindo-se que planos e planejamentos necessitam ser elaborados nas escalas locais e com a participação da população.

Palavras-chave: Planejamento Ambiental. Escala Geográfica. Geografia.

\section{ENVIRONMENTAL PLANNING AND tHE SCALE PERSPECTIVE: A GEOGRAPHICAL APPROACH}

Abstract: This paper aims to reflect on the geographic scale, analyzing it based on its contributions to the understanding of environmental planning in the current context, and from this perspective, to identify possible scalar articulations within the scope of Geography. As methodological procedures were carried out bibliographical surveys of works and authors that discuss these themes. The results obtained allowed to identify that in the scope of the discussion of environmental planning in the scalar perspective, it is important to emphasize that society and nature have different scalar seizures, resulting from distinct rhythms and dynamics, relating to different territories in the interscalar and multiscalar movement. And the dynamic and reciprocal movement between its concrete and abstract elements, are correlated and interrelated, constituting themselves in different scalar perspectives. In any and all planning, there is always a proposal of intervention/political action that refers to a scalar conception of the social world, not always favorable to every society. This situation can be reversed by ensuring that plans and plans need to be elaborated at local scales and with the participation of the population.

Keywords: Environmental Planning. Geographic Scale. Geography.

\footnotetext{
1 Universidade Estadual Paulista (Unesp), Faculdade de Ciências e Tecnologia, Presidente Prudente, Brasil, ricasantos2000@gmail.com, https://orcid.org/0000-0001-9650-8615

2 Universidade Estadual Paulista (Unesp), Campus Experimental de Ourinhos, Ourinhos, Brasil, edson.piroli@unesp.br, https://orcid.org/0000-0002-3350-2651
} 


\section{PLANIFICACIÓN AMBIENTAL Y PERSPECTIVA ESCALAR: UN ENFOQUE GEOGRÁFICO}

Resumen: Este trabajo tiene como objetivo reflexionar sobre la escala geográfica, analizándola en función de sus contribuciones a la comprensión de la planificación ambiental en el contexto actual, y desde su perspectiva, para identificar posibles articulaciones escalares en el alcance de la Geografía. Como procedimientos metodológicos, se realizaron encuestas bibliográficas de obras y autores que discutieron estos temas. Los resultados obtenidos permitieron identificar que en el ámbito de la discusión de la planificación ambiental en la perspectiva escalar, la sociedad y la naturaleza tienen diferentes aprensiones escalares, como resultado de diferentes ritmos y dinámicas, en relación con diferentes territorios en el movimiento inter-escala y multi-escala. $Y$ el movimiento dinámico y recíproco entre sus elementos concretos y abstractos, están correlacionados e interrelacionados, constituyendo diferentes perspectivas escalares. En cualquier planificación, siempre hay una propuesta de intervención / acción política que se refiere a una concepción escalar del mundo social, no siempre favorable para toda la sociedad. Esta situación se puede revertir, asegurando que los planes y planes deben desarrollarse a escalas locales y con la participación de la población.

Palabras clave: Planificación ambiental. Escala Geográfica. Geografía.

\section{Introdução}

As últimas décadas do século $X X$ e início do século $X X I$ foram marcadas por intensas mudanças no quadro mundial, motivadas em grande parte pelo crescimento populacional e pelo processo acelerado de industrialização e urbanização associados ao processo de globalização, predominantemente no circuito do setor corporativo. Essa situação favoreceu uma apropriação intensa da natureza e dos recursos naturais para subsidiar o crescimento econômico no contexto do capitalismo, sobretudo no que se refere a atuação de grandes empresas.

Estas transformações foram ocasionadas como consequência de uma mudança paradigmática no bojo de uma sociedade que passou a conceber a natureza sob a ótica mecanicista originada do cientificismo cartesiano desde o século XVII. Este pensamento passou a difundir a ideia de natureza como um bem utilitário, separando-a do homem e consolidando o paradigma dominante e a antropocentrização do mundo (ALMEIDA; MORAES; SOUZA e MALHEIROS, 1999). É importante destacar que a visão mecanicista da natureza se originou nos pressupostos de Descartes (2006), que favoreceram a disseminação desta como objeto da razão humana, e por isso, passível de ser dominada pelo homem e, consequentemente, como algo externo a ele (FIUGUEIREDO, 2008). 
Este modelo contribuiu para que a natureza fosse visualizada e utilizada na lógica do capital, em que a maior parte é transformada em mercadoria e em bens financeiros. Com base neste cenário, estudos envolvendo o planejamento ambiental se tornam importantes, constituindo-se na atualidade como instrumentos eficazes para pensar a organização do espaço das sociedades, diante de um panorama de crise ambiental mundial que tem afetado e comprometido a qualidade de vida das pessoas. A perspectiva escalar pode contribuir significativamente para a compreensão das atuais dinâmicas sociais, políticas e econômicas que incidem diretamente sobre todos os processos do mundo contemporâneo, incluindo o planejamento ambiental.

Sabe-se que a definição do objeto de estudo da Geografia foi algo muito caro no contexto de sua consolidação como Ciência, confundindo-o muitas vezes com o propósito de estudos de outras áreas do conhecimento, devido a diversas influências que recebeu ao longo de sua constituição. Alguns pesquisadores como Andrade (1992) e Moraes (1987), quando se referem à Geografia e a evolução do pensamento geográfico, concordam que o conhecimento produzido por esta disciplina é antigo. Conquanto, é relativamente recente a sistematização desta, sendo reconhecida academicamente como Ciência autônoma por volta do final do século XIX.

Devido a sua preocupação essencialmente com os fenômenos e sua espacialização desde suas origens, ora produzindo conhecimentos mais voltados para a dinâmica social, ora mais para a dinâmica natural, foi ficando cada vez mais claro seu objeto central: o espaço geográfico.

Atrelada a esta característica peculiar, houve a necessidade fundamental da representação destes fenômenos recorrendo-se aos recursos da Cartografia, com a produção de cartas e mapas como elementos facilitadores das análises e pesquisas. Podem ser destacadas como exemplos, as contribuições da semiótica e da Matemática, com a utilização de elementos visuais e a escala cartográfica para o estabelecimento de uma relação numérica coerente entre os fenômenos da realidade e sua representação; capazes de demonstrar sinteticamente fatos e fenômenos espaciais, de acordo com a área de pesquisa e os objetivos do pesquisador.

São inegáveis as contribuições da Cartografia para a Geografia, sistematicamente para a visualização de fenômenos e análise, permitindo o aprofundamento de estudos científicos. Em contrapartida, emerge no âmbito da 
Geografia, a discussão da escala geográfica como uma necessidade conceitual e metodológica, porém com caráter diferente da escala cartográfica que é restrita a uma relação numérica/matemática (quantitativa), como mencionam alguns autores como Racine, Raffestin e Ruffy (1983), Bahiana (1986), Castro (2000), Souza (2013) entre outros.

Racine, Raffestin e Ruffy (1983, p. 124), enfatizam que "[...] a cartografia é um instrumento disponível, mas não é Geografia”. Castro (2000), ao discutir a escala geográfica, menciona essa preocupação metodológica e epistemológica importante, relacionada à compreensão do sentido e da visibilidade dos fenômenos numa perspectiva espacial. Menciona ainda como preocupação central a essa discussão, a exigência de um nível de abstração, assim também como uma forma de mensuração relacionada à representação dos fenômenos. Melazzo e Castro (2007) destacam que há pouco tempo esta discussão tem recebido atenção por parte dos geógrafos, tornando-a um objeto particular que necessita de investigação por si mesma.

É neste âmbito que este trabalho se insere, tendo como objetivo refletir sobre a escala geográfica, analisando-a com fundamento em suas contribuições para o entendimento do planejamento ambiental na conjuntura atual, e a partir de sua ótica, identificar possíveis articulações escalares no contexto da Geografia. Articulações estas que sob nosso ponto de vista, possuem uma relação dialética entre o concreto e o abstrato que ocorrem paralelamente e concomitantemente, ainda que as pesquisas ambientais predominantemente sejam embasadas no método hipotéticodedutivo. Como procedimentos metodológicos, foram realizados levantamentos bibliográficos de obras e autores que discutem planejamento ambiental e escala geográfica, apoiado em uma abordagem geográfica.

\section{A perspectiva escalar: alguns apontamentos}

Tradicionalmente, na Geografia foi-se construindo uma noção da escala geográfica considerando os recortes institucionalizados do espaço, como, por exemplo, o distrito, o bairro, o município, o estado, o país e o mundo, correspondendo ao nível local, regional, nacional e internacional, como enfatiza Souza (2013). De acordo com este autor, os usos destas palavras são desprovidos de preocupações conceituais, muito atreladas ao senso comum.

De caráter político-administrativo, esses recortes como afirmam alguns autores como Bahiana (1986), Castro (2000), Melazzo e Castro (2007) e Souza 
(2013), significa empobrecer a discussão referente à escala geográfica, ainda que no caso do planejamento ambiental e de outras análises de caráter institucional, esses limites sejam bastante utilizados. Há que se esclarecer que no enredo da discussão da escala geográfica não significa que estes ou outros recortes utilizados como parâmetros para o desenvolvimento de pesquisas tenham que ser abandonados como apontou Souza (2013). Apenas sinaliza que a escala geográfica se transpõe a estes limites por envolver outros fatores que serão discutidos na sequência e que não necessariamente estão "presos" a parâmetros préestabelecidos. Além disso, supõe dinamicidade ao contrário da escala cartográfica.

Aqui pode ser destacada a possibilidade da relação interescalar e multiescalar, de maneira que o nível de apreensão do pesquisador pode interagir com outras escalas, além da sobreposição de escalas que podem ser identificadas em um mesmo território. "Combinar/articular diferentes escalas é um apanágio da pesquisa sócio espacial, mas isso não significa que, em todos os casos, as mesmas escalas e todas as escalas serão 'mobilizadas' com a mesmíssima importância" (SOUZA, 2013, p. 188).

Na concepção de Rivera e Galicia (2016), a escala geográfica remete a uma questão metodológica própria da observação científica, quanto a uma característica objetiva de interações complexas intrínsecas e entre os processos sociais e naturais. Os autores ainda destacam que a reflexão escalar exige uma problematização das representações científicas desses processos, abarcando espaço e tempo, bem como a compreensão de suas características peculiares.

Sobre o uso consolidado de escalas padronizadas que nem sempre traduzem a real dimensão da escala geográfica, Souza (2013) sugere e esclarece alguns critérios e cuidados nos seus usos:

\footnotetext{
Sem dúvida, não há problema em utilizarmos termos como "regional" ou "nacional" para caracterizarmos algumas dessas escalas; o fundamental é entendermos que as escalas de ação não existem, a rigor, anteriormente à própria ação, como se fossem um "dado da natureza" (e mesmo quando, em última instância, o alcance da ação é menos ou mais severamente restringido por instituições e processos preexistentes, que operam em escalas muitas vezes bem delimitadas), da mesma forma como as escalas de análise são (re) construídas, elas próprias, no decorrer do processo de construção do objeto, inclusive devido ao problema de que termos como "nacional" e "regional" precisam, sempre, ser encarados com cautela e ser histórica, política e culturalmente contextualizados (SOUZA, 2013, p. 192).
}

A propósito, qualquer forma de utilização da expressão escala geográfica, seja no modo institucionalizado (caráter político-administrativo), com base no senso comum que é mais conhecido, divulgado e utilizado, ou na expressão de caráter 
mais teórico no âmbito das ciências, objeto de nossa reflexão, se faz necessária a contextualização. Pesquisadores como Smith (1988) e Sposito (2011) enfatizam a ideia de que as escalas geográficas são sistematizadas socialmente, sendo construídas no bojo do modo de produção capitalista e oriundas de relações sociais, de produção, de consumo, de trabalho, mediante conexões e interconexões políticas e econômicas que reorganizam e reestruturam os espaços segundo interesses macroeconômicos. Sob esta ótica, Sposito (2011) destaca que a ampliação dos espaços sob o domínio do capitalismo como modo de produção articulado em escala internacional, possibilita e impõe comparação entre realidades sócio espaciais que se diferem historicamente provenientes de processos diversos, mesmo que este sistema não abranja a totalidade do mundo.

Brenner (2013), ao discutir teoricamente a escala geográfica, aponta que os avanços interdisciplinares recentes sinalizam para o fato de que este conceito passa a questionar seus atributos metodológicos no enquadramento de debates abrangentes proveniente da reestruturação capitalista mundial. Seus argumentos se pautaram em inúmeras contribuições teóricas e empíricas de escritos pioneiros de autores que analisaram questões pontuais referentes a explosão contemporânea dos espaços urbanos, mas também por teóricos que escreveram sobre a cidade global com contribuições da geopolítica econômica crítica.

$\mathrm{Na}$ visão do autor, tais fatores fortaleceram o seu interesse na dimensão escalar em decorrência de processos de reestruturação que foram provocados no contexto do capitalismo histórico e contemporâneo. Em sua concepção, a evolução do sistema capitalista tem ocasionado a reorganização e reestruturação de dinâmicas sócio espaciais contemporâneas que culminaram mais recentemente com a produção da escala geográfica e o processo associado denominado de reescalonamento (podendo ser entendido como processo de reorganização/rearranjo dos vínculos entre escalas geográficas distintas) ou poderíamos dizer na produção de novas escalas geográficas.

Baseado nessa perspectiva, Brenner (2013) propõe os escalonamentos no espaço urbano mediante oito proposições ou fundamentos epistemológicos, como menciona: a necessidade de uma epistemologia crítico-realista de escala; que as escalas resultam de diferenciação e rediferenciação vertical das relações sociais; as escalas existem porque os processos sociais são escalonados; as escalas só podem ser apreendidas de modo relacional; as formas de organização interescalar representam mosaicos e não pirâmides; as configurações interescalares estão 
inseridas em geografias polifórmicas; os processos de reescalonamento são frequentemente condicionados por arranjos pretéritos; e por fim, os processos de reescalonamento redefinem as posicionalidades das formações sócio espaciais e, portanto, reajustam as geografias e coreografias das relações de poder.

Sposito (2011) também sublinha que na atualidade ocorreram crescentes ampliações das relações econômicas em escala internacional em defluência da emergência de novos sistemas técnicos, práticas políticas e interesses de grandes grupos econômicos, ou em outros termos, financeirização e corporativização. Esta conjuntura exigiu ampliar a escala de compreensão das ações e dos fluxos que as revelam e que as sustentam. Destaca ainda a importância de considerar a necessária articulação entre as escalas para compreender o cenário atual sem deixar de admitir sua complexidade e imprevisibilidade no movimento das relações espaço-temporais, redefinindo a dinâmica sócio espacial, vislumbrada cada vez mais como desigualdade sócio espacial.

Para buscar entender estes processos atuais, Santos (2014) sugeriu os conceitos de verticalidades e horizontalidades, atribuindo-lhes um sentido diferente daquele utilizado na Geografia e em outras ciências, ressaltando que o espaço é composto por estes recortes, de forma inseparável. Para ele, as verticalidades estão associadas à lógica global do espaço (objetos esparsos, mas interligados), assegurando o funcionamento macro da sociedade e da economia, atrelados ao meio técnico-científico-informacional. Estas, responsáveis pela circulação, distribuição e consumo num sistema de cooperação mais ampla (econômica e politicamente), afetam diretamente os territórios, ocasionando a organização e reorganização destes, promovendo novos rearranjos espaciais com tendência à homogeneização. Em contrapartida, as horizontalidades estão associadas ao âmbito local (objetos contínuos e contíguos), sendo considerado o lócus da produção, num sistema de cooperação mais limitado (espaço banal, espaço de todas as pessoas, de todas as empresas e de todas as instituições), delineado como um sistema de objetos dinamizado por um sistema de ações predispostos à convergência. Devido à dinâmica da esfera global com sua supremacia à esfera local, este último é exposto à perda da capacidade de gestão da vida local, ainda que não desprovida de conflitos, disputas e associações.

Vainer (2006) aborda a questão das escalas em três dimensões em que sob seu ponto de vista, sempre se faz presente. Primeiramente, nos discursos teóricos (científicos), sendo situados nas formas contemporâneas do capitalismo e sendo 
configurados por ele; segundo, no que denomina de "escala da agência" e "escala de ação política", sinalizando para a necessidade de analisar em qualquer pesquisa, como se articulam dinâmicas e tendências, agências e estruturas, conjunturas e sujeitos que atuam e relacionam-se em diferentes escalas, sem desconsiderar singularidades e generalidades. Com base neste aspecto, o autor destaca que a análise escalar é primordial para compreender o mundo contemporâneo e para transformá-lo. Por fim, o autor direciona seu pensamento aos planejadores urbanos e regionais que se deparam necessariamente com uma questão crucial relativa à qual escala adequada de planejamento, tendo em vista que são inerentes à sua natureza os processos de decisão que determinam sua estruturação, reprodução ou transformação do espaço e que muitas vezes estes se dão em níveis escalares distintos, extrapolando a escala de atuação destes sujeitos. Neste espectro, fica colocada uma preocupação que pode ser preponderante no âmbito de um mundo globalizado, entretanto não determinante.

Observa-se que na compreensão da escala geográfica em suas diversas configurações e resultante de diversos processos, deve-se considerar a conjuntura do mundo contemporâneo. E o mundo contemporâneo, em seus diversos processos, necessita ser interpretado concebendo a perspectiva do modo de produção capitalista que modifica e regula as relações entre sujeitos, instituições, fluxos, mercados, relações de poder, interesses de grandes grupos econômicos, entre outros aspectos como diferenças de poder de consumo, capacidade de decisão ou possibilidade de apreensão do espaço, como apontou Sposito (2011). Estas características têm ocasionado desigualdades sociais e espaciais, repercutindo na produção de diferentes territórios.

Aqui cabe mencionar as contribuições de Smith (1988, p. 139) quando sugere a teoria do desenvolvimento desigual compreendendo-a como "[...] a manifestação concreta da produção do espaço sob o capitalismo" onde as desigualdades geográficas fazem parte da lógica de acumulação do capital. De acordo com o autor, estas características próprias do capitalismo, acarretaram duas tendências contraditórias e concomitantes sobre o espaço: a tendência à diferenciação que se refere à divisão territorial do trabalho que visa a se tornar mais complexo à proporção em que se tornam mais desenvolvidos os estágios do capitalismo em um determinado território; e a tendência à igualização que se dá na intensa necessidade de incorporação tecnológica às forças produtivas, sobretudo ao capital fixo em decorrência da permanente concorrência em que estão submetidas parcelas do 
capital disseminado em vários setores da economia. No que concerne a esta dinâmica, o próprio mercado se encarrega de viabilizar ou impulsionar a equiparação do capital, de maneira a proporcionar condições equitativas de exploração da força de trabalho. Também poderíamos mencionar, embasados nos pressupostos do autor, quando expressa sobre a apropriação da base natural na produção da igualização e da diferenciação.

Sposito (2011) ressalta que na atualidade, nada pode ser compreendido numa mesma escala, mesmo que estejamos nos referindo à escala internacional. Logo, faz-se necessário considerar a articulação entre escalas, além do fato de que cada vez mais o local e outros níveis escalares são determinados pelos interesses da escala global.

Souza (2013, p. 180) salienta que discutir escala geográfica no âmbito da pesquisa sócio espacial supõe considerar "[...] a própria extensão ou magnitude do espaço que está se levando em conta" na perspectiva do alcance e não exatamente numa dimensão métrica/cartográfica. Desta forma, o autor propõe que a escala geográfica deve ser subdividida em escala do fenômeno, escala de análise e escala de ação. A escala do fenômeno se refere à abrangência física do objeto no mundo. Já a escala de análise insere-se entre o objeto real e o objeto do conhecimento, sendo, portanto, intelectualmente construída como um nível analítico, vinculada à apreensão de características que interessam ao pesquisador. Por fim, a escala de ação está atrelada a reflexão do alcance espacial da prática dos agentes, vinculando-se a fenômenos sociais alusivos a ações e a atuação de sujeitos.

Para Souza (2013, p. 188), “ [...] as escalas de análise não são 'dadas': elas são antes 'arrancadas' da realidade no processo de construção do objeto de conhecimento por parte do pesquisador". Esse pensamento nos remete à reflexão de que a escala geográfica é de certo modo, uma apreensão da realidade pelo pesquisador. Tanto é que o mesmo objeto científico pode ser pesquisado em diferentes prismas, e ainda assim, continuará sendo objeto de estudo, pressupondo que a realidade está em constante movimento e transformação.

Admitindo as contribuições e perspectivas que a escala geográfica fornece para o entendimento de qualquer processo no mundo contemporâneo, pretende-se realizar alguns apontamentos, refletindo sobre seus aportes para o entendimento do planejamento ambiental. Além disso, buscar-se-á identificar as possíveis articulações escalares que se inserem no âmbito planejamento ambiental, tendo em vista suas características. 


\section{Planejamento ambiental e a perspectiva escalar}

De acordo com Saraiva (2005), o planejamento ambiental teve origem no início do século XIX com pensadores da Inglaterra, França e EUA. Neste período, em pleno desenvolvimento da Primeira Revolução Industrial, quando se acreditava na inesgotabilidade dos recursos naturais, estes pensadores já demonstravam preocupação com a escassez destes. No Brasil, Santos (2004) destaca que o planejamento ambiental sempre esteve aquém dos países desenvolvidos, fato que contribuiu para a sua não consolidação no país, vivenciando ainda na atualidade um processo de construção de teorias, metodologias e políticas que o embasam, ou adaptando experiências de outras realidades.

Devido às suas características próprias como sua natureza interdisciplinar e integrativa, pode-se afirmar que o planejamento ambiental é considerado como uma atividade estritamente vinculada à Geografia. Isso se deve ao fato de que a particularidade da Geografia como Ciência é analisar os processos que se espacializam e se territorializam no espaço, advindas das inter-relações e interconexões entre as dinâmicas da natureza e da sociedade. Esta similaridade e proximidade entre ambas se dá justamente porque no planejamento ambiental, os fatores a serem considerados são complexos, envolvendo sempre aspectos naturais e sociais.

$\mathrm{Na}$ atualidade, existem diversas definições de planejamento ambiental. Todavia, há um consenso entre a maioria dos teóricos que dentre seus maiores intentos, destacam-se a delimitação de metas, objetivos, estabelecimento de instrumentos e ações adequadas tendo em vista o disciplinamento dos usos dos recursos naturais e da ocupação dos territórios. A esse respeito, Franco (2001) enfatiza que o papel estratégico do planejamento ambiental é o de garantir a preservação e conservação dos recursos naturais e, por consequência, assegurar a sobrevivência da civilização. Além disso, a atuação do pesquisador em Geografia, intervindo na perspectiva do planejamento ambiental, contribui para a minimização de impactos ambientais e promove a interação entre natureza e sociedade e redução dos conflitos oriundos desta relação.

Para Monteiro (2008),

Planejar assenta em prever e prover: prever consequências e prover recursos materiais. Além disso, planejar implica em ordenar, regulamentar, restringir, coibir. Toda essa trama complexa que num aglomerado socialmente heterogêneo implicará em favorecimento a uns, contrariedade a outros (MONTEIRO, 2008, p. 80). 
$\mathrm{Na}$ visão do autor, o planejamento consiste em limitar usos do espaço, mediante conhecimentos obtidos com os estudos, resultando na prática, no que conhecemos por zoneamento ou ordenamento. Implica em prever e prover, além de nem sempre contentar todas as camadas sociais. Nisto reside o aspecto político e econômico que muitas vezes impede que um adequado planejamento ambiental aconteça, privilegiando uma pequena parcela da população que prima por seus próprios interesses.

Santos (2004) relata que a organização do espaço sempre foi uma preocupação desde a antiguidade para grupos de pessoas que se propunham viver comunitariamente com objetivos e normas comuns. Segundo a autora, há registros da preocupação com o planejamento do espaço por aldeias ligadas à prática da pesca ou agricultura que incorporavam no ordenamento do território, aspectos ambientais referentes à topografia e microclima.

Conforme Rodriguez, Silva e Cavalcanti (2007, p. 210), o planejamento ambiental deve ser concebido como "[...] um instrumento articulado ao processo de tomada de decisões para a gestão ambiental no contexto de um determinado modelo e estilo de desenvolvimento [...]. Para os autores, as questões ambientais devem ser incluídas desde o início no processo de planejamento, de forma integrada. Do mesmo modo, concluem que o planejamento ambiental deve ser "[...] integrador, sistêmico, multiopcional e probabilístico [...]".

Para Almeida, Moraes, Souza e Malheiros (1999, p. 13), "[...] o planejamento é um processo rigoroso de dar racionalidade à ação [...]", envolvendo um processo de reflexão, buscando encontrar soluções frente aos problemas que são apresentados. Planejamento é um processo contínuo de pensar ações adequadas para a organização e disciplinamento do espaço, enquanto o plano é a materialização do planejamento, consistindo de objetivos, metas, descrições, cronograma, estratégias de operacionalização, levantamento de custos, entre outros elementos. Sua elaboração, segundo afirma a maior parte dos pesquisadores que atuam nessa área das ciências, é um processo que supõe várias etapas para sua realização. Estas, normalmente são bem semelhantes com poucas variações, se diversificando normalmente nas terminologias, mas que na realidade traduzem os mesmos procedimentos.

Santos (2004) nos dá uma ideia clara no que se fundamenta um autêntico planejamento ambiental e quais suas características esclarecendo que ele: 
[...] consiste na adequação de ações à potencialidade, vocação local e à sua capacidade de suporte, buscando o desenvolvimento harmônico da região e a manutenção da qualidade do ambiente físico, biológico e social. Deve prever e indicar mudanças no uso da terra e na exploração de fontes aceitáveis para as comunidades locais e regionais, ao mesmo tempo em que contemple medidas de proteção aos ecossistemas com pouca interferência humana. Trabalha, enfaticamente, sob a lógica da potencialidade e fragilidade do meio, definindo e especializando ocupações, ações e atividades, de acordo com essas características. As demandas sociais devem ter prioridades sobre as demandas econômicas que, por sua vez, são consideradas, mas dificilmente surgem como um elemento norteador dos planos. Por sua vez, as restrições do meio devem ter prioridade sobre as demandas sociais ou econômicas, ou seja, reconhecem-se as demandas, mas não se avilta o meio, para que elas possam ser atendidas. Deve-se, antes, pensar nas possibilidades de mudança do caráter da demanda (SANTOS, 2004, p. 28).

Santos (2004) define que o planejamento ambiental deve ser organizado e estruturado através da pesquisa (tendo como meta reunir e organizar dados para possibilitar a interpretação da realidade), análise (avaliação dos dados organizados visando a compreensão do meio estudado). Por fim, destaca a síntese (fase de aplicação dos conhecimentos alcançados com o objetivo de propor a tomada de decisões).

Leal (1995) apresenta como proposta de planejamento ambiental, o Plano Motivador. Este Plano busca promover a efetiva participação da população nas iniciativas de planejamentos, visando a melhoria da qualidade de vida local. $\mathrm{Na}$ elaboração do Plano Motivador, o autor indica quatro etapas: inventário, diagnóstico ambiental, prognóstico e propostas.

Apoiando-se nos autores mencionados, é notória a importância do referencial teórico como suporte para o embasamento dos procedimentos metodológicos que neste caso, fazem parte do planejamento ambiental. Este retrata quais paradigmas 0 sustentam e qual visão/modelo de sociedade e ideologias estão implícitas em seus princípios e ações. Esse ponto de vista foi remetido por Vainer (2006), denominando-o como discurso teórico elaborado pela Ciência, compreendendo-o como uma característica da escala geográfica.

Outro aspecto identificado no exercício do planejamento ambiental refere-se à necessária interação entre diversos elementos, ações concatenadas e sequenciais; diferentes aspectos, instâncias de poder e abrangências da realidade, seja de caráter político, econômico, social e ambiental, sendo estes indissociáveis. Essa interação ocorre da relação e correlação entre os diversos elementos, entre diversos atores sociais que atuam em determinados territórios ou que o extrapolam promovendo arranjos espaciais específicos que exercem ou recebem influências de 
outros níveis escalares. É fundamentando-se nesta concepção que se insere a perspectiva escalar (interescalar e multiescalar), atentando-se aos níveis de apreensão do recorte territorial considerado, extrapolando a dimensão cartográfica.

Aqui podemos destacar a contribuição de vários autores que abordam estas dimensões escalares, muito pertinentes ao planejamento ambiental. Inicialmente, podemos ressaltar que o planejamento ambiental pode ser elaborado/implementado em diferentes escalas, seja na esfera local ou internacional, onde ao mesmo tempo sujeitos e instituições que dela participam estão envolvidos com a construção de diferentes escalas. Conceitualmente e metodologicamente, ainda que considerado como um conjunto de procedimentos e técnicas relativamente novas, o planejamento ambiental vem admitindo novas abordagens, contrapondo-se a modelos tradicionais que ainda continuam a coexistir.

Rodriguez, Silva e Cavalcanti (2007) aludem ao planejamento ambiental como incompatível com o planejamento tradicional ou convencional comumente utilizado na atualidade. Para esses autores, este é considerado de caráter setorial, determinista e linear pelo fato de que os sistemas ambientais são encarados como rigidamente projetados, estáveis e constantes, sendo que os componentes são considerados de forma isolada, sem integração.

Hissa (1998, p. 34 e 35) esclarece que os planos tradicionais eram concebidos como peças estanques (como diagnósticos e prognósticos) sendo normalmente elaborados distantes do objeto de intervenção devido a adoção de posturas clássicas da modernidade, explicitamente metodológicas. Segundo o autor, esta distância dá-se decorrente de uma atitude onde o planejador coloca-se a distância do objeto de conhecimento e de transformação, independentemente de sua natureza, atrelados à imparcialidade e objetividade. Outra questão ressaltada e vinculada à primeira, é que se costuma planejar "de cima para baixo" supondo uma "elite pensante" com a incumbência de conhecer e transformar o mundo, distantes daqueles que estariam "dispensados" do trabalho de concepção, planejando-se à revelia do "objeto" que pode ser uma comunidade, um bairro, uma cidade, uma região, ocasionando com que os planos percam a legitimidade, dificultando ou impedindo a construção da relação de identidade entre as estratégias de intervenção e os interessados nas mudanças.

Ainda em conformidade com o autor, como decorrência desta postura metodológica, os planos são colocados em risco de serem abandonados, deturpados e quando implementados, podem determinar intervenções prejudiciais. 
"Os planos deveriam estimular a democracia, desde a sua concepção, com toda a complexidade incorporada à alternativa" (HISSA, 1998, p. 35). Aqui fica evidenciada a supremacia da macro-escala à micro, determinada por relações de poder no espaço, definidas pela lógica do capital que atua globalmente como apontaram Smith (1988), Sposito (2011), Brenner (2013), Souza (2013), entre outros, provocando desigualdades sócio espaciais, excluindo significativas parcelas da população dos processos decisórios e, consequentemente, do acesso às políticas públicas e à qualidade de vida.

Como visibilidade destas premissas, identifica-se que são as parcelas mais pobres da população as maiores vítimas de problemas e desastres ambientais, devido ao fato de que na maioria dos casos, residem em áreas de risco que são descartadas dos interesses do mercado imobiliário. Estas, muitas vezes são ocupadas irregularmente por ausência de políticas habitacionais, ausência ou ineficácia de planejamento em diversos espaços, ausência de incentivos à educação, saúde, à implantação de infraestruturas de saneamento, a programas de combate à pobreza, entre outras ações que expõem as pessoas à vulnerabilidade dos eventos naturais ou sociais (MARICATO, 2015).

Este cenário é ressaltado pelo World Bank e United Nations (2010), quando mencionam que os desastres são resultados de efeitos cumulativos de decisões (individuais e coletivas) referentes ao planejamento do território. E quando estes são associados à ocorrência de eventos naturais de grande intensidade, provocam inúmeros impactos ambientais e socioeconômicos. Como eventos naturais de grande intensidade é possível mencionar inundações, deslizamentos de terra, tempestades, estiagens, incêndios florestais, terremotos ou abalos sísmicos, erupções vulcânicas, entre outros.

Como afirmou Souza (2013), combinar/articular diferentes escalas é um atributo característico das pesquisas que envolvem a análise espacial, ou como ele denomina análise sócio espacial. Portanto, próprio da Geografia. Sua importante contribuição ao mencionar uma subdivisão da escala geográfica remete ao planejamento ambiental. A escala do fenômeno refere-se à compreensão da necessidade de uma delimitação de sua abrangência, ainda que seja possível a interescalaridade, a multiescalaridade e a sobreposição de diferentes escalas. Essa ideia pode ser reforçada pela sugestão que o autor faz de seis escalas ou níveis de abrangência (do corpo; dos "nanoterritórios"; do local sendo subdividido em 
microlocal, mesolocal, macrolocal; regional; internacional sendo subdividido em nacional em grupos de países e global).

Por isto, é possível que planejamentos ambientais sejam elaborados e implementados nestas diferentes escalas sem desconsiderar que uma pode influenciar e incidir sobre as outras. Como exemplo, os planejamentos nacionais podem delimitar parâmetros (legais e institucionais) para estados e municípios. Por outro lado, não se pode descartar como já mencionado que políticas e interesses econômicos na lógica do capital, tentem alterar ou impedir políticas ambientais em nível nacional.

A escala de análise, vinculada à anterior, está atrelada a interpretação ou apreensão que o pesquisador faz nos estudos referentes ao planejamento ambiental. Diferentemente do recorte espacial, este último estaria mais preocupado com os recursos analíticos ou metodológicos quando elenca um ou mais fenômenos específicos envolvendo questões ambientais. Poderia se associar planejamento ambiental e climatologia, planejamento ambiental e geomorfologia, planejamento ambiental e estudos relativos às bacias hidrográficas, entre outros exemplos.

Com mais detalhes, se pode mencionar o planejamento ambiental específico como de uma bacia hidrográfica. De modo geral, a bacia hidrográfica é compreendida como sendo uma área drenada por um rio ou por um sistema fluvial, funcionando como um sistema aberto (CHRSTOFOLETTI, 1980) delimitado por divisores de águas. A legislação brasileira determina a bacia hidrográfica como uma unidade físico-territorial para o planejamento e gerenciamento de recursos hídricos, com fundamento na Lei Federal no 9.433/1997 (BRASIL, 1997), sendo primordial para isso, considerar todos os elementos presentes, sejam eles naturais ou sociais. Não obstante, pode ocorrer que uma mesma bacia hidrográfica esteja concomitantemente em mais de um município ou estado, extrapolando seus limites, o que pode constituir-se num entrave ou solução para implantação de políticas ambientais para sua recuperação ou conservação, possibilitando múltiplas apreensões possíveis. Aqui também se pode vislumbrar a possibilidade da perspectiva escalar, a partir da interescalaridade e multiescalaridade.

Já a escala de ação está mais direcionada aos aspectos políticos e estratégicos concernentes ao papel de agentes/sujeitos que determinam intervenções, interesses e demandas nas diferentes escalas de abrangência. É possível mencionar como exemplo, a proposição de um planejamento ambiental municipal que necessariamente depende de legislação, política e economia, apoio 
técnico entre outros fatores e elementos provenientes do estado e do país, indo além da gestão local. Aqui, há neste aspecto considerado, a transposição de diversos atores sociais originários de vários órgãos de níveis hierárquicos distintos, em que suas ações incidem no município, objeto de estudo, mesmo que não estejam presentes concretamente, mas que de alguma forma se materializam. Podese considerar um exemplo de relação interescalar contemplando relações intrínsecas entre diferentes instâncias e atores sociais e também multiescalar, contemplando realidades diversas e por vezes distantes umas das outras.

Estas subdivisões da escala geográfica relacionadas por Souza (2013) foram paralelamente sugeridas por Vainer (2006) como "escala da agência" e "escala de ação política”, e reporta-se ao papel das instituições e atores sociais na perspectiva escalar. Mas questiona qual a escala apropriada de planejamento que possibilitaria a não prevalência de outros níveis escalares e sujeitos que dificultariam ações significativas de transformação na escala local.

Como mencionado anteriormente, tanto as relações sociais, políticas e econômicas incidem sobre determinados territórios produzindo e reproduzindo objetos, tal qual como as relações entre os diversos elementos naturais que se diferenciam variando no tempo e no espaço e se inter-relacionam. Ambos objetos (sociais ou naturais) exercem influências uns sobre os outros. Esse conjunto é referido por Santos (2014), ao buscar explicar o espaço geográfico como sistema de objetos e sistema de ações. O autor expõe que estes são indissociáveis, solidários e contraditórios. Neste quadro, pode-se compreender que cada elemento (social, natural) possui níveis escalares diferenciados e que por sua vez são produtores de escalas geográficas peculiares com abrangências diversas. Ainda pode-se afirmar que o tempo contém uma escala geográfica diferente do espaço, conforme destaca Haesbaert (2006).

Nesta discussão, é importante ressaltar que sociedade e natureza possuem apreensões escalares díspares, resultantes de ritmos e dinâmicas distintas. Enquanto a natureza é associada ao tempo longo (escala geológica, referindo-se a processos resultantes de duração de milhares ou milhões de anos), os processos sociais são relacionados ao tempo curto (relativo ao tempo histórico, associados à presença do homem e da sociedade como promotores de modificação de paisagens e transformadores do ambiente). (SANT'ANNA NETO, 2013; SUERTEGARAY; NUNES, 2001). Este entendimento é fundamental para se evitar diversos conflitos na sociedade atual que resultam da não compreensão destes diferentes ritmos e 
dinâmicas, especialmente quando a sociedade acreditava ou ainda acredita ser possível que a natureza pudesse se adequar aos seus padrões, ou a sua performance.

Rivera e Galicia (2016), ao discutirem o conceito de escala geográfica, compreendem-no como um elemento epistemológico que necessita ser redimensionado para a compreensão dos problemas socioambientais. Esta abordagem sugere que estes não podem ser analisados desconsiderando métodos que relacionem adequadamente os processos que os compõem em diferentes escalas temporais e espaciais, além dos diferentes níveis de organização, diferentes paradigmas disciplinares e de identificação das unidades de análise. E com base em seus elementos, requerem novas perspectivas metodológicas. Outros aspectos destacados pelos autores, é que para melhor compreensão de um fato geográfico, dada a sua dinamicidade e abrangência, é comum a utilização de estratificações espaciais para analisar o objeto de estudo de forma separada, conforme diversos critérios. Como os problemas socioambientais não se originam nas mesmas condições hierárquicas, também não são visíveis nas mesmas escalas operacionais, oriundos de processos sociais e biofísicos não proporcionais ou correspondentes entre si.

Desse modo, a solução e a compressão de diferentes aspectos, exigem estudos de processos que ocorrem em diferentes escalas de espaço, tempo, organização ecológica e socioeconômica, sendo o conceito de escala, unificador, possibilitando entender as inter-relações dos fatos que são estruturados hierarquicamente. Portanto, o esforço para a compreensão do conceito de escala geográfica, permite verificar diferentes formas de uso dos elementos escalares como instrumentos epistemológicos e metodológicos para a construção de objetos geográficos delimitados, ao mesmo tempo que integram conhecimento produzido em diferentes campos do conhecimento, garantindo um caráter disciplinar (RIVERA; GALICIA, 2016).

Para Racine, Raffestin e Ruffy (1983), enquanto a escala cartográfica expressa a representação do espaço como forma geométrica (relação numérica/matemática entre o objeto e sua representação), a escala geográfica retrata a relação das sociedades com estas formas geométricas. Sendo esta última, portanto, mais dinâmica e de certo modo, concreta e abstrata. Isto posto, pode-se compreender que ambas características se expressam paralelamente e 
concomitantemente, num movimento contraditório, em um tempo e espaços determinados, portanto em um movimento dialético.

Sob nosso ponto de vista, a abordagem da perspectiva escalar na Geografia remete também a antiga discussão entre o todo e as partes, resultante de uma visão de mundo originada nas convicções do positivismo e neopositivismo. Este pensamento que predominou nas ciências, inclusa a Geografia, até meados do século $X X$, contribuiu para a disseminação da concepção de uma realidade fragmentada, como se a totalidade fosse uma simples junção das partes, onde estas não se relacionavam.

Esse cenário no contexto da Geografia, remonta suas origens, evidenciando que as pesquisas sempre buscavam compreender a totalidade, por meio do movimento da indução e da dedução. Apesar deste esforço, os procedimentos científicos utilizados resultavam em um conhecimento desprovido da realidade social, sendo na maioria das vezes descritivo e superficial, sem significativos avanços para a compreensão do todo.

Esse esforço na Geografia por fomentar estudos e análises integrativas da realidade no planejamento ambiental são oriundas da abordagem sistêmica que tem influenciado predominantemente estudos e pesquisas de caráter ambiental, sobretudo nas proposições da Geografia Física. De acordo com Christofoletti (1990), a abordagem sistêmica originou-se da Teoria Geral de Sistemas que buscava explicar que os fenômenos naturais são organizados como sistemas abertos, que se baseiam na troca de matéria e energia, na tentativa de compreender a natureza na inter-relação entre seus elementos. Essa teoria busca superar a particularização dos estudos científicos ao propor uma abordagem holística dos fenômenos naturais, enfatizando que os sistemas funcionam mediante a um equilíbrio dinâmico, sendo este rompido com novo aporte de matéria e energia, que busca uma nova situação de equilíbrio nessa nova situação.

$\mathrm{Na}$ Geografia, disseminou-se a teoria geossistêmica, derivada dos sistemas. Esta foi concebida na década de 1960 pela influência da escola russa através da produção intelectual de Sotchava e difundida no mundo ocidental pela escola francesa e pelos estudos de Bertand na mesma década (RODRIGUES, 2001). Com sua consolidação, esta teoria vem evoluindo e adquirindo nuances de outras influências teóricas e tendências do mundo contemporâneo.

Em relação a esta teoria, Rodrigues (2001) destaca que: 
[...] a teoria geossistêmica faz parte de um conjunto de tentativas ou formulações teórico-metodológicas da Geografia Física, surgidas em função da necessidade de a Geografia lidar com os princípios de interdisciplinaridade, síntese, com a abordagem multiescalar e com a dinâmica, fundamentalmente incluindo-se prognoses a respeito desta última (RODRIGUES, 2001, p. 72).

Como frisado pela autora, os princípios de interdisciplinaridade e síntese onde está implícito o esforço holístico, retrata o necessário vínculo com a abordagem multiescalar e a dinâmica, característica da realidade em constante transformação e evolução. Desse modo, percebe-se que a discussão da escala geográfica tem muito a contribuir para a superação deste problema (todo-partes), considerado por Bahiana (1986) uma questão filosófica fundamental, ainda alvo de discussão na atualidade.

À medida que a perspectiva interescalar e multiescalar compreende um movimento recíproco entre elementos concretos e abstratos, que se correlacionam e se inter-relacionam, e não estão presos estritamente a delimitação de territórios, pode-se compreender que o todo está contido de certa forma na parte e a parte está contida no todo. Nesta discussão do movimento dos elementos concretos e abstratos, destaca-se a importante contribuição de Kosik (2002) quando explana sobre fenômeno e essência.

Ao distinguir fenômeno de essência, na busca da compreensão da realidade, Kosik (2002) acentua que aquilo que é visualizado, não necessariamente retrata a essência do objeto estudado, sendo necessário conhecer suas estruturas embasada nos postulados da dialética. Para isso, afirma que:

[...] A característica precípua do conhecimento consiste na decomposição do todo. [...] O conhecimento se realiza como separação de fenômeno e essência, do que é essencial, já que só através dessa separação se pode mostrar a sua coerência interna, e com isso, o caráter específico da coisa. [...] Esta decomposição do todo, que é elemento constitutivo do conhecimento filosófico - com efeito, sem decomposição não há conhecimento [...] (KOSIK, 2002, p. 18).

Por outro lado, não descarta a importância do fenômeno, considerando a manifestação da essência como sua atividade, embora ao mesmo tempo, pode escondê-la, já que a essência não se dá imediatamente. Contudo, fica subentendido que o movimento científico de apreensão da realidade não é algo simples e que a realidade é complexa.

Carlos (2009) defende que o conhecimento, entendido em sua visão como a capacidade de construir uma compreensão sobre o mundo moderno, deve ser estabelecido com a ruptura de preconceitos às diferenças e ao que denomina de 
"estado de intolerância". Mas destaca que o conhecimento deve ser construído com o esforço coletivo dos geógrafos, sendo necessária a crítica ao saber construído. Esse seria o caminho, de acordo com a autora, para se chegar à totalidade:

Se o conhecimento contempla sua própria crítica, também é necessário considerar que ele aponta em direção à totalidade, colocando para todos a necessidade de superar as fragmentações necessárias, mas não absolutas, do ato de conhecer. Refiro-me às especializações que rompem a unidade do conhecimento, quando cada qual se afirma afastando-se do outro (CARLOS, 2009, p. 73).

Um outro aspecto referido pela autora, é que estudar particularidades (partes) no que ela denomina de especializações no campo científico, no contexto da Geografia, não é algo considerado errôneo. Mas sinaliza para romper a fragmentação dentro das especializações quando o conhecimento produzido deixa de remeter à unidade do conhecimento (todo), sem contextualizá-lo ou se esquivar da possibilidade do diálogo e das inter-relações possíveis com diferentes campos do saber. Fica claro que a busca da totalidade não exclui a especialização, mas quando suprime a possibilidade de aproximação e de diálogo entre diferentes saberes.

O planejamento ambiental necessita do conhecimento da dinâmica do meio físico (geologia, clima, geomorfologia, solos, cobertura vegetal e hidrografia) e socioeconômico (densidade demográfica, renda, escolaridade, usos da terra, estudos da dinâmica populacional e caracterização econômica) apropriando-se de diversas técnicas e estudos específicos da área estudada. Conhecendo os fenômenos, buscando identificar e caracterizar a essência, os reais problemas por meio dos levantamentos realizados, é possível planejar, visualizar cenários e possibilidades de melhoria do território estudado.

Admitindo estas características inerentes ao planejamento ambiental, pode-se afirmar que no seu processo de elaboração e implementação, transita por níveis escalares (interescalar e multiescalar) diferentes a partir da dinâmica natural e social. Enquanto dinâmica natural (meio físico) busca compreender seus mecanismos de funcionamento, a inter-relação entre os diversos elementos naturais que geram diferentes combinações por meio das características específicas de cada espaço. Pode-se dizer que transita também pelos níveis escalares da dinâmica social relacionada às instâncias de poder administrativo do território institucionalizadas (município, estado, país) em que sua elaboração e implementação estão diretamente atreladas a um determinado modelo de gestão ambiental (campo político, legislação, execução de políticas públicas e ambientais, entre outros aspectos), determinado sua eficácia ou não. Uma vez que as influências 
do meio natural e social na realidade não se encontram desassociadas, produzem perspectivas escalares por intermédio da forma como essas diferentes dinâmicas se comportam, se influenciam e se combinam.

Aqui, pode-se assinalar que as metodologias próprias do planejamento ambiental são predominantemente originárias do método hipotético-dedutivo, todavia, identifica-se hoje uma possibilidade de associá-lo ao método dialético. Considera-se que esta associação propicia uma maior abrangência de metodologias e técnicas, contribuindo para uma melhor leitura e interpretação da realidade. Em vários estudos recentes sob esta perspectiva, são consideradas as contradições típicas à sociedade no bojo do sistema capitalista, além de serem valorizadas a historicidade e os aspectos sociais das relações estabelecidas na área, objeto de estudo.

Em relação à discussão todo-partes, observa-se que o planeamento ambiental busca diálogo entre diversas áreas do conhecimento empenhando-se em associar conhecimentos do meio físico e socioeconômico, suas dinâmicas e interrelações. Vale-se de conhecimentos da Geografia Humana e Geografia Física, e por isso, contribui na ciência geográfica para a compreensão da totalidade.

Doravante, ante às problematizações elencadas neste texto, cabe-nos buscar responder a seguinte indagação: a articulação da política de planejamento ambiental gera de fato efeitos no recorte territorial? Podemos dizer que sim e sob diversos aspectos, conforme buscou-se refletir. É possível afirmar que as diferentes escalas geográficas na perspectiva do planejamento ambiental são produzidas como resultantes das inter-relações e da combinação de diferentes elementos e atores sociais com níveis hierárquicos distintos promovidos em parte pelas instâncias de poder do território em diferentes dimensões, apreensões ou das necessidades do pesquisador com um olhar sobre outra ótica ou perspectiva.

\section{Considerações finais}

Posto que o esforço de diversos geógrafos em discutir a escala geográfica seja um fato na atualidade, esta reflexão necessita ser amadurecida sob o ponto de vista metodológico e epistemológico, pensamento destacado pelos autores analisados. Na tentativa de se compreender a escala geográfica diferentemente da escala cartográfica, verifica-se equívocos e evidências de confusão no uso e aplicabilidade dos termos, embora que não seja excluída a delimitação de territórios, de modo que não se perca a dimensão de diversos componentes que se combinam 
e se articulam. Tal fato demonstra o caráter de transposição, extrapolação, dinamicidade e por consequência, rearranjos espaciais próprios da perspectiva escalar sem perder de vista que os processos do mundo global refletem diretamente sobre o local, não sendo mais possível excluir em qualquer análise, esta perspectiva.

Este quadro reporta ao fato de que não é possível compreender a dinâmica da realidade, desconsiderando-se o modo de produção capitalista vigente. Este é produtor de cenários de diferentes dinâmicas sócio espaciais e desigualdades sociais como consequência da prevalência dos interesses e decisões de agentes econômicos e políticos, articulando níveis escalares diferentes, onde os interesses da escala local são muitas vezes deixados de lado. Do ponto de vista dos estudos ambientais, estes normalmente são relegados a um plano secundário para atender a lógica mercadológica do capital. Vale salientar nesse processo, a supremacia da sociedade contemporânea à dinâmica da natureza que necessita ser paulatinamente superado.

Em relação ao planejamento ambiental, constatou-se a necessidade deste relacionar-se a diferentes territórios no movimento interescalar e multiescalar, mesmo que o objeto de planejamento seja um espaço específico, delimitado. Aqui fica evidenciado que apesar da escala geográfica ser diferente da escala cartográfica mais remetida e "aprisionada" aos limites territoriais numa dimensão numérica e geométrica, a primeira não descarta a territorialização, justamente por seu movimento dinâmico e recíproco entre elementos concretos e abstratos que se correlacionam e se inter-relacionam constituindo diferentes perspectivas escalares.

Outro fator importante a ser mencionado é que o objeto de estudo da Geografia é o espaço geográfico, e por isso, a escala geográfica não pode ficar distante dessa essência. Ainda assim, a representação cartográfica sendo ferramenta importante para o desenvolvimento de pesquisas, por si não dá conta de realizar a análise crítica e abrangente da realidade. Desse modo, fica claro que a escala geográfica está diretamente relacionada às necessidades do pesquisador e as características do seu objeto de estudo, sofrendo influências dos fatores histórico, social, político, econômico e do meio físico.

Convém salientar, como sugeriu Sposito (2011), que se faz necessário trabalhar no plano teórico e empírico desprendendo-se das perspectivas escalares vinculadas aos interesses econômicos que muitas vezes não representam majoritariamente os interesses da sociedade. Aqui é oportuno resgatar a 
preocupação de Vainer (2006), quando questiona aos planejadores, qual a melhor escala para se elaborar um planejamento.

Conquanto, pode-se considerar que a escala geográfica está associada à observação do pesquisador e às apreensões que eles fazem da realidade, sendo necessário estabelecer parâmetros. Nesta contextura, vale ressaltar o que apontou Carlos (2009), ao expressar que as especializações são necessárias no âmbito das ciências e da Geografia, sem, entretanto, deixar de relacionar o conhecimento produzido à unidade do conhecimento (todo), contextualizando-o e possibilitando o diálogo e as inter-relações possíveis com diferentes campos do saber.

No caso específico do planejamento ambiental, remetendo-se a preocupação de Vainer (2006, p. 17) quando destaca que "[...] por trás, ou à frente, de toda proposta de intervenção/ação política está presente, subjacente ou não, explícita ou não, uma concepção escalar do mundo social, isto é, das formas predominantes de produção e reprodução de relações [...]" com propostas nem sempre favoráveis à sociedade. Sob nosso ponto de vista, esta situação pode ser revertida garantindo-se que os planos e planejamentos sejam elaborados nas escalas locais e com a participação da população.

Esse processo ganhará visibilidade conforme a sociedade se apropriar de um direito preconizado em legislação, legitimando sua participação em todas as decisões no âmbito das gestões locais ou de outras instâncias, garantindo que seus direitos sejam considerados, evitando que interesses macro predominem. Embora a tradição na participação da população em resolução de problemas, elaboração de planos e projetos, particularmente relativos aos problemas ambientais, seja algo conquistado recentemente no país com o processo de democratização empreendido desde a década de 1980, há que se reivindicar e se estabelecer canais que garantam de fato esta atuação, fomentando que esse processo possa ser validado e consolidado.

\section{REFERÊNCIAS}

ANDRADE, M. C. Geografia, ciência da sociedade: uma introdução a análise do pensamento geográfico. São Paulo: Atlas, 1992. 143 p.

ALMEIDA, J. R.; MORAES, F. E.; SOUZA, J. M.; MALHEIROS, T. M. Planejamento Ambiental: caminho para participação popular e gestão ambiental para o nosso futuro comum. Uma necessidade, um desafio. Rio de Janeiro: Thex Editora, 1999. 161 p.

BRASIL. Lei Federal no 9.433, de 08 de janeiro de 1997. Institui a Política Nacional de Recursos Hídricos, cria o Sistema Nacional de Gerenciamento de Recursos Hídricos, 
regulamenta o inciso XIX do art. 21 da Constituição Federal, e altera o art. 1ํ da Lei no 8.001, de 13 de março de 1990, que modificou a Lei no 7.990, de 28 de dezembro de 1989.

BAHIANA, L. C. C. Contribuição ao estudo da questão da escala na Geografia: escalas em Geografia Urbana. 200 f. 1986. Dissertação (Mestrado em Geografia). Universidade Federal do Rio de Janeiro. p. 1-93.

BRENNER, N. Reestruturação, reescalonamento e a questão urbana. In: GEOUSP, São Paulo, n. 33, 2013, p. 198-220.

CARLOS, A. F. A. Da "Geografia abstrata" à "Geografia concreta". In: MENDONÇA, F. A.; LOWEN-SAHR, C. L.; SILVA, M. (orgs.). Espaço e tempo: complexidade e desafios do pensar e do fazer geográfico. Curitiba: Associação de Defesa do Meio Ambiente e Desenvolvimento de Antonina (ADEMADAN), 2009. p. 73-90.

CASTRO, I. E. de. O problema da escala. In: CASTRO, I. E. de; GOMES, P. C. da C.; CORREA, R. L. (orgs.). Geografia: conceitos e temas. $2^{\underline{a}}$ ed. Rio de Janeiro: Bertrand Brasil, 2000. p. 117-140.

CHRISTOFOLETTI, A. Geomorfologia. São Paulo: Edgar Blücher, 1980. 188 p.

CHRISTOFOLETTI, A. A aplicação da abordagem em sistemas na Geografia Física. In: Revista Brasileira de Geografia, São Paulo, n. 52, 1990. p. 21-35. Disponível em: http://biblioteca.ibge.gov.br/visualizacao/monografias/GEBIS\%20\%20RJ/RBG/RBG\%201990\%20v52_n2.pdf. Acesso em: 14 jan.2017.

DESCARTES, R. Discurso do método. São Paulo: Ícone, 2006. 94 p.

FIUGUEIREDO, T. Sentir, pensar e agir. A Educação Ambiental na perspectiva biocêntrica. Revista Pensamento Biocêntrico, Pelotas, n. 9, jan./jun./2008. p. 85 - 110.

FRANCO, M. A. R. Planejamento ambiental para a cidade sustentável. São Paulo: Annablume/FAPESP, 2001. 296 p.

HAESBAERT, R. Territórios alternativos. 2ª ed. São Paulo: Contexto, 2006. 186 p.

HISSA, C. E. V. Geografia e planejamento: entre o puro e o aplicado. In: GEONOMOS, Belo Horizonte, v. 6 n. 2, 1998, p. 33-43.

LEAL, A. C. Meio ambiente e urbanização na microbacia do Areia Branca - Campinas São Paulo. 1995. 155 f. Dissertação (Mestrado em Geociências) - Instituto de Geociências e Ciências Exatas, Universidade Estadual Paulista, Rio Claro, 1995.

MARICATO, E. Para entender a crise urbana. São Paulo: Expressão Popular, 2015. 112 p.

MELAZZO, E. S; CASTRO, C. A. A escala geográfica: noção, conceito ou teoria? In: Terra Livre, Presidente Prudente, ano 23, v. 2, n. 29, ago/dez. 2007. p. 133-142. Disponível em: http://www.agb.org.br/publicacoes/index.php/terralivre/article/view/244/228. Acesso em: 05 jan. 2018.

MONTEIRO, C. A. F. O homem, a natureza e a cidade: planejamento do meio físico. Geografar, Curitiba, v. 3, n. 1, jan./jun.2008. p. 73-102. Disponível em: https://revistas.ufpr.br/geografar/article/view/12911/9192. Acesso em: 05 jan. 2018.

MORAES, A. C. R. de. A gênese da Geografia moderna. $1^{a}$ ed. São Paulo: Editora Hucitec, 1987. 206 p. 
KOSIK, K. Dialética do Concreto. São Paulo: Paz e Terra, 2002. 248 p.

RACINE, J. B.; RAFESTIN, C.; RUFY. Escala e ação: contribuição para a interpretação do mecanismo de escala na prática da Geografia. In: Revista Brasileira de Geografia, Rio de Janeiro, ano 45, n. 1, jan/mar. 1983, p. 133-145.

RIVERA, N. R.; GALICIA, L. La escala geográfica como concepto integrador en la comprensión de problemas socio-ambientales. In: Investigaciones Geográficas, Coyoacán, Boletín no 89, Instituto de Geografía, UNAM, México, 2016, p. 137-153.

RODRIGUES, C. A teoria geossistêmica e sua contribuição aos estudos geográficos e ambientais. Revista do Departamento de Geografia da USP, São Paulo, n. 14, 2001. p. 69-77.

RODRIGUEZ, J. M. M.; SILVA; E. V.; CAVALCANTI, A. P. B. Geoecologia das paisagens: uma visão geossistêmica da análise ambiental. Fortaleza: Edições UFC, 2007. 222 p.

SANT'ANNA NETO, J. L. Escalas geográficas do clima: mudança, variabilidade e ritmo. In: AMORIM, M. C. C. T. A.; SANT'ANNA NETO, J. L. MONTEIRO, A. (orgs.). Climatologia Urbana e Regional: questões teóricas e estudos de caso. São Paulo. Outras Expressões. 2013. p.75-91.

SANTOS, R. F. Planejamento ambiental: teoria e prática. São Paulo: Oficina de Textos, 2004. 184 p.

SANTOS, M. A natureza do espaço: técnica e tempo, razão e emoção. $4^{a}$ ed. São Paulo: Edusp, 2014. 384 p.

SARAIVA, F. Considerações acerca da pesquisa em Geografia Física aplicada ao planejamento ambiental a partir de uma perspectiva sistêmica. In: RA'EGA - O Espaço Geográfico em Análise, Curitiba, n. 9, 2005. p. 83-93. Disponível em:

https://revistas.ufpr.br/raega/article/view/3449/2726. Acesso em: 04 dez. 2017.

SMITH, N. Desenvolvimento desigual. Rio de Janeiro: Bertrand Brasil, 1988. 250 p.

SOUZA, M. L. de. Os conceitos fundamentais da Pesquisa Sócio-espacial. Rio de Janeiro: Bertrand, 2013. 319 p.

SPOSITO, M. E. B. A produção do espaço urbano: escalas, diferenças e desigualdades socioespaciais. In: CARLOS, A. F. A; SOUZA, M. L de; SPOSITO, M. E. B. (org.). A produção do espaço urbano: agentes e processos, escalas e desafios. São Paulo: Contexto, 2011, p. 123-145.

SUERTEGARAY, D. M. A.; NUNES, J. O. R. A natureza da Geografia Física na Geografia. Revista Terra Livre, São Paulo, n. 17, 2ํㅗㄴ semestre/2001. p. 11-23.

VAINER, C. B. Lugar, região, nação, mundo: explorações históricas do debate acerca das escalas da ação política. Revista Brasileira de Estudos Urbanos e Regionais, Curitiba, v. 8, n. 2. Nov. 2006. p. 9-29.

WORLD BANK. UNITED NATIONS. Natural hazards, unnatural disasters: the economics of effective prevention. Washington: The International Bank for Reconstruction and Development/The World Bank, 2010. 254 p. Disponível em:

http://documents.worldbank.org/curated/pt/620631468181478543/pdf/578600PUB0epi2101p ublic10BOX353782B.pdf. Acesso em: 04 dez. 2017. 


\section{NOTAS DE AUTOR}

\section{CONTRIBUIÇÃO DE AUTORIA}

Ricardo dos Santos - Concepção e elaboração do manuscrito, participação ativa da discussão dos resultados. Edson Luís Piroli - Orientação, revisão e aprovação da versão final do trabalho.

\section{FINANCIAMENTO}

Não se aplica.

\section{CONSENTIMENTO DE USO DE IMAGEM}

Não se aplica.

\section{APROVAÇÃO DE COMITÊ DE ÉTICA EM PESQUISA}

Não se aplica.

\section{CONFLITO DE INTERESSES}

Não se aplica.

\section{LICENÇA DE USO}

Este artigo está licenciado sob a Licença Creative Commons CC-BY-NC. Com essa licença você pode compartilhar, adaptar, criar para qualquer fim, sem uso comercial e desde que atribua a autoria da obra.

\section{HISTÓRICO}

Recebido em: 07-02-2020

Aprovado em: 05-05-2020 